\title{
Preparing For Using Augmentative and Alternative Communication in Classrooms: Pre-Service Special Education Teachers' Perceptions
}

\author{
Rashed A. Aldabas \\ Dept. of Special Education, College of Education, King Saud University \\ PO BOX 2458, Riyadh 11451, Saudi Arabia \\ E-mail: Raldabas@ksu.edu.sa
}

Received: August 1, 2017 Accepted: Nov. 3, 2017 Published: November 3, 2017

doi:10.5296/jse.v7i4.12062 URL: https://doi.org/10.5296/jse.v7i4.12062

\begin{abstract}
The purpose of this study was to examine pre-service special education teachers' perceptions regarding their skills and knowledge about the use of $\mathrm{AAC}$, with respect to how well it prepared them to use AAC with students who have severe communication impairments. A descriptive research design was used to address the research questions. A total of 27 special education pre-service teachers (emphasized whether Early Childhood Special Education or Intellectual Disabilities) completed an online survey. The findings indicate that participants responded positively about their knowledge, ability, skills, and attitudes about teaching and using AAC for students with severe communication disabilities. However, the results found that the majority of participants felt their preparation programs were not adequate in preparing them to implement and use AAC in classrooms. Although the participants felt more confident in their ability to teach students who use AAC, the general consensus was that more preparation training would be helpful in the classroom and with the students themselves. More implications for practice and recommendations for future research are discussed.
\end{abstract}

Keywords: Augmentative and alternative communication, severe disabilities, communication impairments, special education teacher Preparation programs 


\section{Introduction}

Currently, there is a mandate for providing free appropriate public education (FAPE) for all students with disabilities, including those who have severe communication impairments (U.S. Department of Education, 2010). FAPE encourages the education of such students to be performed in general educational settings. As a result, inclusive education has progressed and is available to all students with disabilities. However, students with severe communication impairments may be unable to attend general schools and so are deprived of services and support for their physical, emotional, social, and intellectual needs (Light, Arnold and Clark 2003, as cited in Page and Quattlebaum, 2012). Certain types of disabilities are commonly associated with significant needs and challenges related to communication. These are categorized as severe and/or multiple disabilities (SMD) due to their being associated with significant challenges such as communication difficulties and challenging behaviors (Collins 2007). Disabilities of these types could include autism spectrum disorders (ASD), intellectual disability, deaf-blindness and communication impairments. Educational decision-makers have taken several steps to support and enhance the education of these students, including creation of communication interventions to improve their communication and social skills. In particular, augmentative and alternative communication systems (AAC) have been made available to enhance their communication capabilities (Zangari, Lloyd, and Vicker, 1994).

The American Speech-Language-Hearing Association (ASHA) has defined AAC as the means to "compensate for temporary or permanent impairments, activity limitations, and participation restrictions of individuals with severe disorders of speech-language production and/or comprehension, including spoken and written modes of communication" (2001). AAC was initially viewed as an important extension of traditional notions of speech therapy as those being treated did not have to acquire significant skills to communicate appropriately (Zangari et al., 1994). With the application of AAC to support communication of individuals with cognitive impairments, it essentially became a way to teach (Zangari et al., 1994). AAC would enhance inclusion of students with severe disabilities in general classrooms (Hourcade et al., 2004). As well, Light and McNaughton (2013) indicated that AAC systems are effective in increasing communication and social interaction for students having severe communication impairments. AAC methods have been found effective with individuals having ASD (Ganz et al., 2012). King, Hengst and DeThorne (2013) demonstrated that integrating AAC with traditional speech intervention is effective in improving communication and natural speech production goals.

AAC systems are of two types, aided and unaided. Unaided systems do not employ any external tool and include body language, facial expression, sign languages, and vocalizations (Beukelman and Mirenda, 2005, p. 36) whereas aided AAC systems include any "device, either electronic or non-electronic, that is used to transmit or receive messages" (Beukelman and Mirenda 2005, pp. 4-5). Aided AAC, integrates external sources such as pictures, drawings, letters, numbers, books, computers, electronic devices, and words (Mirenda, 2005; Partridge 2009). High-tech computers used in AAC not only feature keyboards, touch screens, and switches but also technology that tracks eye movement and/or head movement (Partridge, 2009). Aided systems are categorized by level of complexity (Ganz, 2014; Ganz et al., 2012). 
Successful implementation of AAC systems requires a variety of elements (Ogletree, 2007). The National Research Council [NRC] (2001) has set forth a number of guidelines for integrating communication supports into educational programs, including early intervention employing AAC, low teacher-to-student ratios, collaboration with families, integration of AAC into regular classroom instruction, measurement of performance goals, and adjustment to programming as necessary (NRC 2001; Ogletree, 2007, p. 191). However, implementation of AAC faces a variety of barriers, including limited teacher training, inadequate preparation time, negative teacher attitudes, and stress, all of which increase teachers' difficulty in providing appropriate education (Finke, McNaughton and Drager, 2009; Kent-Walsh and Light, 2003). These barriers include lack of training, inadequate skills, unclear roles, limited resources, and lack of collaboration between schools and parents as well as among the members of an educational team (Kent-Walsh and Light, 2003). Also, a student's success with using AAC is partly dependent upon the perceptions and attitudes of adults inside or outside of the classroom. Finke et al. (2009) found that teachers of students who used AAC had positive perceptions regarding teaching their students, and supported inclusion of the students in general classrooms as well as increased social interactions among students. Teacher perceptions have been found to be a significant factor in the successful inclusion of students using AAC (Kent-Walsh and Light, 2003).

Integrating the use of AAC in classrooms can present challenges for teachers due to difficulty in selecting appropriate $\mathrm{AAC}$ systems, in the use of $\mathrm{AAC}$, and in continuous collaboration with other education team members as well as family members (Soto, Müller, Hunt, and Goetz, 2001a). Teachers' views of their responsibilities for teaching students with disabilities are another factor that affects inclusion of AAC in classrooms (Soto 1997). According to Soto, Müller, Hunt, and Goetz (2001b), educators must also develop a supportive classroom community in which cooperative learning, team teaching, sharing of information, and advocacy work together to create a strong learning environment supporting the use of AAC (pp. 54-55). Hunt, Soto, Maier, Müller, and Goetz (2002) suggest that the specialized yet limited experiences of speech language pathologists (SLP) or special education teachers may limit any real application or integration of AAC into general classrooms. Thus, adequate training and preparation are key factors for teachers who have students using AAC in their classrooms (Koul and Lloyd, 1994; Ratcliff, Koul, and Lloyd, 2008). Bailey, Parette Jr., Stoner, Angell, and Carroll (2006) found that lack of skills in using AAC devices was linked to general teachers' reluctance to teach those students.

Hence, teacher's skills and knowledge about AAC are essential to educating students with severe communication impairments in general classrooms. Koul and Lloyd (1994) stated that professional training programs provided through special education, SLP programs lack contents in AAC. Costigan and Light (2010) pointed out that undergraduate programs offered for special education teachers, SLP, and occupational therapists are insufficient in preparing them to use ACC and teach students who use an AAC system. AAC courses do not cover all the needed content of AAC (Costigan and Light, 2010). Similarly, Subihi (2013) concluded that pre-service special education teachers do not receive adequate training and coursework in AAC during their preparation programs. Andrews (2007) also indicated a lack of skills in 
how to teach students who use AAC and the consequent need to offer more professional development addressing needed skills for AAC use. Not only do these lacks affect the ability of educators to teach students who use AAC, but also they can negatively impact their attitudes toward integrating $\mathrm{AAC}$ into teaching.

As perspectives shifted, the field of education began looking for ways to open the doors to communicative and academic opportunity through the use of both unaided and aided AAC systems for communication. Studies have shown that the implementation of AAC resources early in a student's educational experience has the potential to improve the user's academic skills, communication skills, and social skills throughout his or her lifetime (e.g. Chung et al., 2012; Chung and Douglas, 2014; King and Fahsl, 2012; Light and McNaughton, 2012; Millar et al., 2006; Rispoli et al., 2010; Soto et al. 2001a; Stoner et al., 2006; Zangari et al., 1994). Based on previously mentioned studies, the effectiveness of AAC systems has been addressed and has resulted in communication enhancements for students with severe communication impairments. The literature review also found that much research has been done examining teachers' use of AAC in their classrooms and what challenges teachers face while teaching students who use AAC. The challenges of implementation of AAC include teachers` lack of knowledge, skills, resources, and support (Alkahtani, 2013; Alquraini, 2014; Andrews, 2007; Costigan and Light, 2010; Hanline et al., 2012; Nigam and Koul, 2009; Soto, 1997; Soto et al., 2001a).

In addition, research has studied the competencies and skills that teachers should have in order to be qualified to teach students who use AAC, including knowledge of needs, characteristics and challenges of the students, knowledge of assessments, knowledge of implementation of AAC, collaboration, and parent involvement (Alquraini, 2014; Andrews, 2007; Bailey et al., 2006; Costigan and Light, 2010; Hanline et al., 2012;Koul and Lloyd, 1994; Nigam and Koul, 2009; and Soto, 1997;Soto et al., 2001a). However, no consensus has been reached on what special education teachers need to be ready to teach these students (Courtade and Ludlow, 2008). The literature review showed that few studies have addressed special education teacher preparation programs, i.e., how teachers are actually prepared to teach students who use AAC. For example, Costigan and Light (2010) rviewed studies addressed to preparation programs offered for special education teachers, occupational therapists, and SLP. Likewise, Koul and Lloyd (1994) conducted a survey on the preparation training on AAC offered through colleges and universities and found the training was not enough and did not cover all AAC content. The studies both of Costigan and Light (2010) and of Subihi (2013)found that special education teacher preparation programs do not offer sufficient training in AAC. However, most studies that were reviewed addressed special and general education teachers' as well as other professionals' perceptions towards using AAC (e.g. Alkahtani, 2013; Alquraini, 2014;Andrews, 2007; Hanline et al. 2012; Nigam and Koul 2009; Soto, 1997; Soto et al., 2001a; Soto et al., 2001b).

To conclude, the literature review found that previous research did not examine the perceptions of pre-service special education teachers regarding their skills and knowledge about the use of AAC and teaching students who use AAC. This study investigated whether pre-service special education teachers perceive the same barriers that general teachers 
perceive. Thus, the current study may reveal useful information on how special education teacher preparation programs can prepare teachers to apply AAC systems in addressing the needs of students. This investigation of pre-service special education teachers 'perceptions regarding their skills and knowledge with respect to AAC might be a contribution to the field.

\section{Method}

\subsection{Participants and Setting}

A total of 27 pre-service special education teachers participated in this study. The participants were in the last semester of their program at the time when this study conducted. Of these, 17 $(63 \%)$ were enrolled in Early Childhood Special Education (ECSE) pre-service teachers and $10(37 \%)$ were enrolled in Instructional Strategists II: Intellectual Disabilities (ISID) pre-service teachers. The participants had completed one or both of the following courses during their programs at the university: Introduction to Assistive Technology or Augmentative Communication. Convenience sampling, a type of non-probability sampling, was the selection method chosen for this study because the participants were available and represented characteristics that were needed for the study (Bhattacherjee, 2012; Fraenkel and Wallen, 2009). This study was conducted at one of the United States of America universities. The university offers bachelor degrees, master's degrees and doctoral degrees in a variety of areas in arts, humanities, natural sciences, social and behavior sciences.

\subsection{Research Questions}

The specific research questions for this study were:

1. How knowledgeable and skilled do pre-service special education teachers perceive themselves to be, regarding the use of Augmentative and Alternative Communication systems and devices (AAC) for students with severe communication impairments?

2. What are pre-service teachers' perceptions of the special education program that they had completed with respect to how well it prepared them to use AAC with students who have severe communication impairments?

\subsection{Research Design}

A descriptive research design was used in this study. According to Crano and Brewer (2002) surveys offer "real-world context and the availability of mass data in developing information about human actions" (p.17). The survey in this study examined personal perceptions of pre-service special education teachers toward the use of AAC. The descriptive study "provides descriptive accounts targeted to understanding a phenomenon using data that might be collected in a variety of ways, such as interviews, observations, and document review" (Ary, Jacobs and Razavieh, 2010 p.29).

\subsection{Instrument}

The researcher developed a survey based on three previous surveys. A study of Soto in 1994 measured special education teachers' attitudes toward the use of AAC by students with severe communication impairments (SCI). Most items of the survey were modified from Soto's 
survey. Other questions in the survey were drawn from the study of Rebelowski (2003), who measured paraprofessionals' perceptions toward working with young students who used AAC and a study of Andrews (2007) that examined the knowledge and attitudes of general education teachers toward AAC. Based on the previously mentioned studies and the review of the literature, the researcher developed a new survey for this study using a Likert Scale: Strongly Agree $=5$, Agree $=4$, Neutral $=3$, Disagree $=2$, and Strongly Disagree $=1$. The new survey was a two-part document. The first part collected demographic information regarding the participants' emphasis areas emphasis areas (i.e., ECSE and ISID). The second part consisted of 32 questions that the participants answered by using a 5-point Likert scale, excepted questions 7 which asks to select a disability or more that may benefit from AAC, and 24 which asks to select a type of AAC that a participant is familiar. Both were in a multiple-choice format in which the participants could select more than one answer. The 32 statements pertained to four different areas: (a) pre-service special education teachers' perceptions of their knowledge regarding the specific characteristics, needs and challenges of students with SMD; (b) pre-service special education teachers' perceptions of their ability to access, implement and utilize AAC; and (c) pre-service special education teachers' perceptions of their ability to conduct assessments to determine students' specific communication needs and match a method of AAC to a specific student; and finally, (d) pre-service special education teachers' general perceptions of the use of AAC, such as inclusion of students who use AAC in general classrooms and collaboration with others in teaching those students.

\section{5 Validity of the Survey Instrument}

In this study, validity was established by conducting an expert review (Lynn, 1986). It is recommended by Ary et al. (2010) that in using a Likert Scale for a survey, "a diverse collection of items" should be generated through the consultation of experts, which can help shape the tone of the survey and avoid any "negative statements" (p. 209). The experts for this study are professors at the university; one in the Department of Communication Disorders and an expert in AAC as well as in communication disorders. The other professors are in the Department of Special Education and are experts in severe disabilities and/or assistive technology. In the first stage of development the questionnaire contained 38 items. The expert review members were asked to critique each item to determine if it measured the content under consideration. Recommendations were made for deleting some items and rewording others. On recommendation of the experts, six items were removed from the survey. Based on the expert review members' suggestions, the researcher also revised wording for many items in the survey.The revised survey with 32 items was sent again to the expert review panel, and there was agreement to approve the validity of the survey. Additionally, five graduate students in the special education program were asked to complete the instrument and had no questions or problems with understanding or interpreting items.

\section{6 Reliability of the Survey Instrument}

Reliability measures the internal consistency of a survey. In this study, reliability was established by employing the split-half method after collecting the data 
(Bhattacherjee,2012).It measures the extent to which all parts of the questionnaire contribute equally to what is being measured(Bhattacherjee, 2012). The instrument's reliability was measured after the data were collected. Because the instrument has two multiple-choice questions, the questions totaled 44 items. Question 7 was divided into eight parts and Question 24 into six questions for statistical purposes. There were 22 items in the first half of the survey and 22 in the second half (see Table 1). The entire testing instrument was administered to all 27 participants. The Spearman-Brown coefficient was 0.454, which showed a low reliability (Ary et al., 2010; Fraenkel \& Wallen, 2009). However, Cronbach's Alpha coefficient is recommended for use with Likert scale questions or with questions that have more than one answer for measuring reliability (Ary et al., 2010; Fraenkel and Wallen, 2009). Thus, the Cronbach's Alpha coefficient was applied to determine the spilt-half reliability of the survey (Fraenkel and Wallen, 2009). The Cronbach Alpha coefficient for the first half was 0.727, which indicated a moderately acceptable reliability (Ary et al., 2010; Fraenkel and Wallen, 2009). The Cronbach Alpha coefficient for the second half was 0.677 that showed an acceptable reliability (Ary et al., 2010; Fraenkel and Wallen, 2009). The Spearman-Brown coefficient showed lower internal reliability (0.454) for several reasons, such as a small sample size and low heterogeneity affect the reliability of the instrument survey (Ary et al., 2010; Fraenkel and Wallen, 2009). Therefore, the above factors might have caused the survey`s low reliability.

Table 1. Reliability Statistics of the Survey Instrument

\begin{tabular}{l|l|l}
\hline Cronbach's Alpha Part 1 & Value & 0.727 \\
Nurt 2 & Value & $22^{\mathrm{a}}$ \\
& Number of Items & $22^{\mathrm{b}}$ \\
Total number of & 44 \\
Correlation among forms & items & 0.677 \\
Spearman-Brown Coefficient & Equal Length & 0.454 \\
\hline
\end{tabular}

\subsection{Data Collection Procedure}

After obtaining approval from the university Institutional Review Board, the researcher sent a general e-mail to all the sample of this study. They were 27 pre-service special education teachers who have worked on or have completed the Early Childhood Special Education program and/or Instructional Strategist II: Intellectual Disabilities program offered at the 
university. This e-mail introduced these individuals to the study (including the purposes and how to participate, along with a web link for completing the Informed Consent form and online questionnaire) and invited them to participate in the study. The questionnaire was completed online using www.google.com/forms, and the link for the questionnaire listed in the invitational e-mail. The online survey is comfortable to open and complete; as a result, obtaining more responses (Fricker and Schonlau, 2002). The questionnaire took approximately 10-15 minutes to complete. After a week, the researcher sent a reminder e-mail to all those who had not yet responded about participating in the study, and asked them to consider completing the online questionnaire.

\subsection{Data Analysis Procedure for the Survey}

Based on the data obtained from the participants on the 32-question survey, the researcher determined the mean, frequencies, percentages and standard deviations. Responses were entered into the SPSS (version 18) data analysis program for this general statistical analysis. Descriptive statistics was used to answer the study questions.

\section{Findings}

\subsection{The Demographic Information of the Participants}

A total of 27 pre-service special education teachers participated in this study. Of these, 17 $(63 \%)$ were ECSE pre-service teachers and 10 (37\%) were ISID.

Table 2. Descriptive Data for Pre-Service Special Education Teachers' Perceptions of Using AAC for Students with SMD

\begin{tabular}{|c|c|c|c|c|c|c|c|c|}
\hline Item & & $\begin{array}{l}\text { Strongly } \\
\text { Disagree }\end{array}$ & Disagree & Natural & Agree & $\begin{array}{l}\text { Strongly } \\
\text { Agree }\end{array}$ & $M$ & $S D$ \\
\hline \multirow{2}{*}{$\begin{array}{l}\text { 1. Students with SMD have } \\
\text { difficulties in starting a } \\
\text { conversation. }\end{array}$} & $n$ & 0 & 3 & 3 & 13 & 8 & \multirow[t]{2}{*}{3.9630} & \multirow[t]{2}{*}{0.9398} \\
\hline & $\%$ & 0 & 11.1 & 11.1 & 48.1 & 29.6 & & \\
\hline \multirow{2}{*}{$\begin{array}{l}\text { 2. Students with SMD have } \\
\text { learning difficulties plus } \\
\text { communication difficulties. }\end{array}$} & $n$ & 0 & 3 & 5 & 13 & 6 & \multirow[t]{2}{*}{3.8148} & \multirow[t]{2}{*}{0.9214} \\
\hline & $\%$ & 0 & 11.1 & 18.5 & 48.1 & 22.2 & & \\
\hline \multirow{2}{*}{$\begin{array}{l}\text { 3. Behavior problems of } \\
\text { students with SCI may be a } \\
\text { result of their } \\
\text { communication difficulties. }\end{array}$} & $n$ & 2 & 4 & 0 & 9 & 12 & \multirow{2}{*}{3.9259} & \multirow{2}{*}{1.3280} \\
\hline & $\%$ & 7.4 & 14.8 & 0 & 33.3 & 44.4 & & \\
\hline \multirow{2}{*}{$\begin{array}{l}\text { 4. Students with SCI cannot } \\
\text { establish relationships due } \\
\text { communication difficulties. }\end{array}$} & $n$ & 4 & 11 & 1 & 7 & 4 & \multirow[t]{2}{*}{2.8519} & \multirow[t]{2}{*}{1.3785} \\
\hline & $\%$ & 14.8 & 40.7 & 3.7 & 2.59 & 14.8 & & \\
\hline $\begin{array}{l}\text { 5. Students with SMD have } \\
\text { limitations in }\end{array}$ & $n$ & 2 & 5 & 3 & 12 & 5 & 3.4815 & 1.2207 \\
\hline
\end{tabular}


communication and social skills.

6. Students with SMD have the right and potential to communicate. be aware of developing communication skills.

9. Improving important area in teaching the students.

10. Ability to develop communication goals.

11. Preparation courses have made me aware of the needs of SMD.

12. Ability to find and develop social interventions involving students' use of AAC.

13. Knowledge the different types of assistive technology, AAC.

14. I need more training on implement AAC. $\% 7.4$ 18.5

n 0 $\% 0$

0

$\% 0$

$\begin{array}{ll}n & 1\end{array}$

\% 3.7

n 0

$\% 25.9$

n 0

$\% 0$

n 0

$\% 0$

n 1

$\% 3.7$

n 0

$\% 0$

3.7

n 1

$\% 3.7$

3.7

22.2

4

14.8

13
8. Important for teachers to communication skills is

11.1

$44.4 \quad 18.5$

0

2

25

$\begin{array}{lll}0 & 7.4 \quad 92.6\end{array}$

4.9259

0.2668

$3 \quad 22$

4.6667

0.8721

$3.7 \quad 11.1 \quad 81.5$

0

7

20

$4.7407 \quad 0.4466$

$25.9 \quad 74.1$

$15 \quad 5$

$3.7037 \quad 1.0309$

3.7

$55.6 \quad 18.5$

13

9

3.7

48.1

4.0000

1.0000

6

6

1

2.7407

0.9842

$\begin{array}{llll}48.1 & 22.2 & 22.2 & 3.7\end{array}$

15. AACs enable students for

n 0

0

3.7

18

7

$66.7 \quad 25.9$

succeeding academically and socially.

$13 \quad 11$

16. Difficulty of using AAC

n

without support from administrators, general teachers $\% 0$ or paraprofessionals.

11.1

$48.1 \quad 40.7$

17. More likely to be successful $n \quad 0$ in AAC in students ' daily lives if parents are involved.
$8 \quad 19$

$29.6 \quad 70.4$

$8 \quad 15$

$4.2962 \quad 0.9928$ 0.4653
$6 \quad 19$

$22.2 \quad 70.4$ 
18. Comfortable working with $\quad n \quad 0$ a speech-language pathologist (SLP) and knowable how to use $\% \quad 0$ AAC.

19. A lack of professional training on AAC would be a significant factor in any reluctance toward teaching a $\% \quad 0$ student with AAC.

20. Preparation courses provided me with the knowledge on assessing communication skills of n 0 5 18.5 1 $10 \quad 11$ students with SMD. meeting the specific student's needs.

22. Necessary to collaborate with appropriate professionals in selecting AAC.

23. Necessary to collaborate with appropriate professionals in teaching students needing $\mathrm{AAC}$, how to use it.

25. Beneficial to collaborate with SLP

26. Collaboration with the IEP team regarding AAC would be most effective.

27. Special education teachers are fully responsible for teaching students with SMD.

n 2

$\% \quad 7.4$

7.4

n $\quad 0$

0

$\% \quad 0$

n $\quad 0$

$\% \quad 0$

63

22.2

$\begin{array}{ll}7.4 & 7.4\end{array}$

$2.5925 \quad 0.9306$

$4.4814 \quad 0.8024$

$$
6
$$

$2 \quad 2$

$4.0000 \quad 1.1094$

4.4814 0.8024


enables them to be more independent.

31. Students using AAC would be more accepted by others as AAC helps to communicate.

\begin{tabular}{|c|c|c|c|c|c|c|c|c|}
\hline $\begin{array}{l}\text { enables them to be more } \\
\text { independent. }\end{array}$ & $\%$ & 0 & 0 & 0 & 25.9 & 74.1 & & \\
\hline $\begin{array}{l}\text { 31. Students using AAC } \\
\text { would be more accepted by }\end{array}$ & $n$ & 0 & 1 & 3 & 12 & 11 & \multirow[b]{2}{*}{4.2222} & \multirow[b]{2}{*}{0.8006} \\
\hline $\begin{array}{l}\text { others as AAC helps to } \\
\text { communicate. }\end{array}$ & $\%$ & 0 & 3.7 & 11.1 & 44.4 & 40.7 & & \\
\hline $\begin{array}{l}\text { 32. AAC should be accessible } \\
\text { throughout full range of daily }\end{array}$ & $n$ & 0 & 0 & 0 & 4 & 23 & \multirow[b]{2}{*}{4.8518} & \multirow[b]{2}{*}{0.3620} \\
\hline $\begin{array}{l}\text { settings and routines for the } \\
\text { students. }\end{array}$ & $\%$ & 0 & 0 & 0 & 14.8 & 85.2 & & \\
\hline
\end{tabular}

\subsection{Findings of the Research Questions}

\subsubsection{Research Question 1}

Research question one asks how knowledgeable and skilled pre-service special education teachers perceive themselves regarding the use of AAC for students who have severe communication impairments. In this question, participants were asked to respond to 23 survey items using a Likert scale of 1-5. First, Table 2 presents the mean $(M)$, standard deviation (SD) and frequency $(n)$ for the 23 items that concerned participants' perceptions of how well they understand the characteristics and challenges linked to SMD, and heir comfort level in their role as a special education teacher of the students. The mean is the average of the participants' responses, where a score of one represents strong disagreement and a five represents strong agreement. Thirteen participants agreed in that students with SMD have difficulties for establishing a conversation. They $(n=13)$ also likely agreed with item 2 , with a mean of 3.8148 and SD 0.9214. There are 9 agreements and 12 strong agreements in that students with SCI may express challenges due to difficulties with communicating and sharing their feelings. The participants were neutral to agreeing that students with SMD have limitations in speech and social skills. Twelve participants also disagreed in that studentswithSCIcannotestablishrelationshipsbecauseoftheircommunicationdifficulties. They $(n=25)$ strongly agreed on that improved communication and social skills are important in teaching students with SMD. In addition, the results showed there are 23 strongly agreements in that the important of being aware of the development of language and communication skills $(M=4.6667, S D=0.8721)$. Twenty agreements in that improved communication and social skills are important areas of teaching the students. Table 3 shows that the majority of the participants believed that students with autism, developmental disabilities, intellectual disabilities, multiple disabilities, deaf-blindness, traumatic brain injury, communication impairments or speech or language impairments might benefit from using AAC. Overall, the participants had high positive attitudes toward being special education teachers of students with SCI. 
Table 3. Participants` Responses to Item 7

Which of the following disabilities do you think may benefit from AAC: Frequency

Autism

Developmental disabilities

Intellectual disabilities

Multiple disabilities

Deaf-blindness

Traumatic brain injury

Communication impairments

Second, to measure participants ' perceptions toward their ability to access, implement, and utilize AAC, the mean, $S D$ and frequency of their responses to the items relating to skills of AAC implementation and accessing (item 18), and their attitudes toward the use of AAC (items 15, 16 and 17) were calculated. Back to Table 2, the participants likely have positive attitudes toward the use of AAC. They were close to strongly agreeing $(n=19)$ in that AAC enables students with SCI to achieve success academically as well as socially $(M=4.7037$, $S D=0.4653$ ). Fifteen participants strongly agreed and eight others agreed in that using AAC would be difficult without support from administrators, general teachers, or paraprofessionals. Participants strongly agreed $(n=19)$ or agreed $(n=6)$ in the importance of parent involvement for successful usage of AAC. Of participants $(n=21)$ felt positively comfortable working with SLP in improving communication skills of the students and knowing how to use AAC $(M=4.0000, S D=1.1094)$. However, this statement may have caused some confusion because it attempted to measure in one statement.

In measuring the participants' perceptions of their ability to conduct assessments to determine students' specific communication needs and to match AAC to a specific student, the mean, $S D$ and frequency of their responses to the items $22,23,24,25,26$ and 27 were analyzed. Table 2 indicates that participants have positive attitudes toward collaboration with professionals in conducting communication needs assessments and matching AAC to students. The participants $(n=27)$ positively agreed in that it is necessary to collaborate with appropriate professionals in making referrals and decisions $(M=4.7777, S D=0.4236)$. They $(n=23)$ also strongly agreed that it is necessary to collaborate in teaching students how to use AAC $(M=4.8518, S D=0.3620)$. Twenty-six agreed in that it is more beneficial to collaborate with SLP to set goals and select AAC for students than to work independently. Similarly, Twenty-three strongly agreed that collaboration with the IEP team to select and develop communication interventions for a student would be the most effective AAC $(M=4.8518$, $S D=0.3622)$. The majority of participants $(n=15)$ strongly disagreed that special education teachers are fully responsible for teaching the students how to communicate whether verbally or non-verbally $(M=1.4814, S D=0.5798)$. 


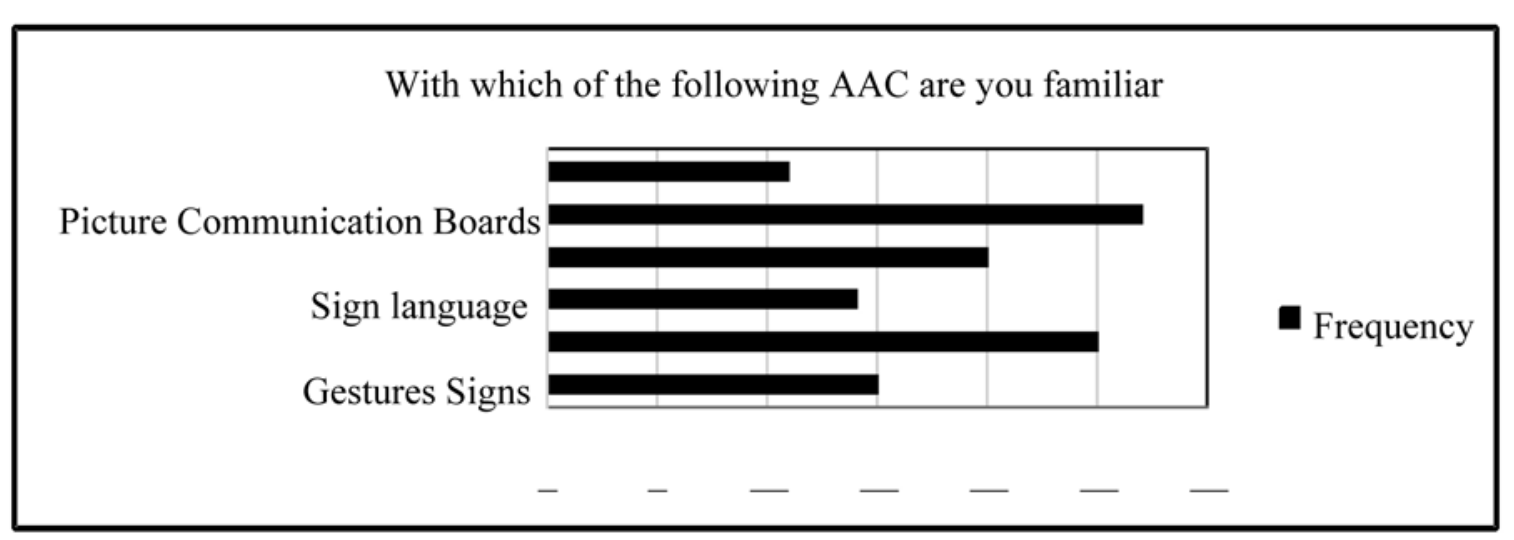

Figure 1. Participants` Responses to Item 24

Figure 1 indicates that all of the participants $(n=27)$ were familiar with picture communication board methods, $(n=25)$, with signs, $(n=20)$, AlphSmart album, $(n=15)$, gestures and $(n=11)$ and electronic systems. These results indicate that when AAC is high tech, it became more complicated to use. It also can be stated that most of the participants were familiar with AAC methods between low and mid tech.

Finally, the survey items 29-32 concerning participants' perceptions of the impact of using AAC. Participants $(n=17)$ were likely to agree in that supporting students with AAC requires excessive amounts of time and effort from teachers and support personnel $(M=3.6923$, $S D=1.175)$. They also were likely to strongly agree $(n=20)$ that using AAC for the students enables them to be more independent. Twenty-three positively agreed that students using AAC would be more readily accepted by others as hey would be more able to communicate. Of participants, 23 expressed a strong agreement responding to that students should have access to AAC throughout their full range of daily settings and routines $(M=4.8518$, $S D=0.3620)$.

\subsubsection{Research Question 2}

Research question five asks pre-service special education teachers to evaluate the quality of the special education program they completed with respect to how well it prepared them to use AAC with students with SCI. To answer this question, responses to these nine survey items $(10,11,12,13,14,19,20,21$ and 28$)$ were analyzed by the mean $(M)$, standard deviation $(S D)$ and frequency $(n)$.

For analytical purposes, these nine items of the survey were divided into three categories: (1) items concerning their perceptions of whether their college courses provided them with adequate knowledge about the characteristics and challenges of the students. This category sought further to learn whether the participants thought their courses prepared them to develop communication goals for the students (items 10 and 11); (2) items concerning their perceptions on how their college courses prepared them to teach students who use AAC (items 12,13,14 and 19); and (3) items relating to their perceptions about their college courses on how they provided the knowledge to conduct assessments of communication needs and identify AAC to a specific student (items 20, 21 and 28).

By observed Table 2, findings indicated that the participants were between neutral and 
agreement that their preparation program provided them with effective knowledge on the characteristics, needs and challenges of students with SMD. Twenty responses were positive compared to six were disagreements responded to item 10 (I am able to develop communication goals for the students. The participants reported positive agreement $(n=22)$ in that their education courses had made them aware of the needs and abilities of students with SMD. Participants $(n=14)$ disagreed in that I am able to find and develop social and communication interventions that involve students' use of AAC $(M=2.7407, \mathrm{SD}=0.9842)$. However, participants $(n=25)$ positively agreed that they knew the different types of assistive technology, including AAC: low tech, mid tech and high tech. Participants also reported positive agreement $(n=24)$ that they need more training to learn how to implement $\operatorname{AAC}(M=4.1851, S D=0.9622)$.

Most of the participants $(n=24)$ positively agreed that a lack of professional training about how to implement AAC would be the most significant factor in any reluctance toward teaching a student using $\mathrm{AAC}(M=4.4814, S D=0.8024)$. As well, 17 of participants disagreed negatively that their education courses provided them with the knowledge of how to assess communication skills $(M=2.5925, S D=0.9306)$. The majority $(n=16)$ reported disagreements toward the ability to identify a method of AAC for a specific student. The participants $(n=17)$ also disagreed negatively in their knowledgeable to evaluate the appropriateness and effectiveness of AAC $(M=2.2962, S D=0.1372)$.

\section{Discussion}

The first finding of this study demonstrated that the pre-service special education teachers who participated in it have positive perspectives toward the abilities with students with SMD, including those SCI. This indicates that the participants were positive in their willingness to teach students who use AAC and they have positive attitudes toward the students' abilities and needs. This finding is linked to a finding of Soto (1997) that teachers' perceptions of their students' capabilities affect the use of AAC in their classrooms. Findings regarding perceptions about the impact of using AAC with the students indicate that the participants have positive perceptions about the results of using AAC, and this supports the use of AAC in classrooms (Alquraini, 2014; Andrews, 2007; Soto, 1997). It can be stated that ECSE and/or ISID preparation coursework contents concentrate more on severe disabilities including severe communication impairments. These findings suggest that participants who received more training concerning the needs and challenges of students with severe disabilities felt more efficient and positive about teaching those students (Hanline et al., 2012; Soto, 1997). This suggests that because the participants from ISID program will be teachers of students with intellectual disabilities who may have severe communication difficulties, their pre-service training program should offer more subjects related to AAC. However, the findings conclude that all participants stated a lack of professional training in how to implement AAC would negatively affect willingness to teach students who use AAC. This is supported by previous studies (Alquraini, 2014; Andrews, 2007; Hanline et al., 2012; Soto, 1997; Soto et al., 2001a).

This study further indicated an interesting finding regarding perceptions toward collaboration. The participants reported that collaboration with other school professionals 
such as the IEP team is important in assessing the communication needs of students who need to access AAC and in implementing AAC in classrooms. This finding confirms results of Soto et al. (2001a) that addressed perspectives of educational professionals about the use of AAC in inclusive classrooms. This shows that the participants are willing to collaborate with SLP to successfully use AAC in their classrooms. This finding is supported by findings of Finke at al. (2009) and Soto et al. (2001b) that collaboration is considered by teachers to be an essential skill for using AAC in classrooms. It further indicates that preparation coursework provided to the participants covered more content about the collaborative approach. The participants saw parent involvement as positively supportive of successful use of AAC for students with SCI. This finding point out that collaboration and parent involvement enhance the efficiency of using AAC in classrooms (Bailey et al., 2006; Finke et al., 2009; Soto et al., 2001a; Soto et al., 2001b).

Another finding indicated that the majority of the participants responded positively that they had been provided sufficient courses addressed to the needs and challenges associated with SMD. The results indicate that the participants felt their ability to differentiate between the types of AAC, ranging from low to high tech, was adequate. On the other hand, current study results showed that most participants stated they did not gain sufficient knowledge and skills related to AAC content through their preparation program. These skills and abilities include: assessing communication needs of students, developing social and communiaction interventions involving the use of AAC, identifying and evaluating the effectiveness of a method of AAC that meets student's specific communication needs and implementation of AAC. These findings are consistent with those of previous studies examining teacher education training on AAC (e.g. Costigan and Light, 2010; Koul and Lloyd, 1994; Nigam and Koul, 2009; Subihi, 2013). For instance, Costigan and Light (2010) reviewed studies on pre-service training in AAC offered for SLP, special education teachers, and occupational therapists, and concluded that the pre-service training in AAC was not adequate and not supportive enough for them to successfully use it. This was the sentiment of the pre-service teachers who participated in this study as well.

As a final point, the findings pointed out that participants are in need of training programs addressing the content of AAC. It also reaffirmed the conclusion of a study conducted by Nigam and Koul (2009) and another conducted by Subihi (2013) that there is a need for more courses and training in AAC for pre-service special education teachers. As well, these findings agree with findings of Koul and Lloyd (1994) stated that preparation training on AAC offered through colleges and universities is insufficient and does not cover all AAC content. Results discussed previously also indicated that participants' pre-service training programs had offered coursework that focused more on characteristics of individuals with SMD than on AAC contents. This is also supported by the findings of previous studies (Andrews, 2007; Alquraini, 2014; Hanline et al., 2012; Nigam and Koul, 2009; Soto, 1997). Which revealed that challenges of implementation of AAC in classrooms consist of teachers ' lack of knowledge, skills, resources, and support. Accordingly, there is a need to provide more contents that cover skills in communication assessments and interventions, including skills in how to access and implement AAC whether through courses specific to AAC or 
merged with other courses (Costigan and Light, 2010; Koul and Lloyd, 1994; Subihi, 2013). This suggests that pre-service special education teachers' preparation programs should provide ongoing opportunities for practicing along with courses in the AAC field to support them in transferring what they learn to their classrooms (Costigan and Light, 2010; Soto, 1997).

\section{Implications of Study Findings}

The findings of this study indicated that the majority of the participants felt positive about their knowledge, skills, and attitudes about teaching and using AAC with students who have severe communication problems. However, the findings also pointed out that more training programs related to AAC are needed. Although the participants felt more confident in their ability to teach students who use AAC, the general consensus was that more preparation training would be helpful in the classroom and with the students themselves. This would indicate that more contents and subjects related to AAC should be offered for pre-service special education teachers through their preparation programs. These subjects provide more concentration in improving pre-service teachers' abilities in communication assessment and interventions as well as in accessing and implementing AAC (Costigan and Light, 2010; Koul and Lloyd,1994; Soto, 1997; Subihi, 2013).

This study supports the suggestions from previous research that special education teacher preparation programs should design courses to cover essential skills in using AAC in classrooms and insert contents related to AAC into other special education courses (Costigan and Light, 2010; Koul and Lloyd,1994; Subihi, 2013). For example, the participants of this study mentioned that they were not able to develop social intervention to support the use of AAC, were not able to identify an appropriate method of AAC and were unable to implement $\mathrm{AAC}$ in classrooms. Even though the participants had been enrolled in assistive technology courses and/or AAC courses, they stated that their college coursework had not provided them with sufficient knowledge in the field of AAC. Therefore, courses should be planned to focus more on how to develop communication and social intervention as well as how to identify different types of AAC methods and then match an appropriate method to meet the specific needs of an individual student. Moreover, courses should be created to prepare teachers to implement AAC and teach students who need AAC how to use it, inside or outside the classroom.

In addition to designing courses in AAC, special education preparation programs should offer more opportunities for pre-service teachers to practice in actual classrooms involving the use of AAC (Soto, 1997). This would enable pre-service teachers to transfer what they learn from coursework to practice, to close the gap between practice and coursework and to be more ready to use AAC and teach students using it. This would raise a need to collect data about how many students use or need AAC in classrooms. Data needed to be collected include how to assess, design and assign appropriate AAC to students. These data help to make connections between teacher education and schools, in order to prepare qualified teachers to teach those students. Therefore, there is a need to improve or redesign courses addressed to educating students with severe disabilities who use AAC. The scope of the courses should be 
widened to cover training to assess communication skills of students with severe communication impairments. In fact, all special education teacher preparation programs, and especially those preparing teachers of children with severe disabilities including early childhood, intellectual disabilities, multiple disabilities and developmental disabilities which may affect communication abilities, should be included with coursesemphasizing AAC (Page and Quattlebaum, 2012).This study suggests that leaders in the field of special education teacher preparation programs should develop more extensive preparation programs to address all the skills and knowledge related to AAC in which the participants reported less self-confidence (Costigan and Light, 2010; Koul and Lloyd,1994; Subihi, 2013). In the preparation of future special education teachers, learning about accessing and implementing AAC, as well as teaching students how to use it, should be addressed. This study brings up the fact that collaboration with other educational professionals is important to successfully teach students with SCI. Accordingly, stakeholders in special education preparation programs should maintain positive perceptions of collaboration by addressing more approaches of collaboration in teaching and team-working skills throughout the coursework and practicum. This would enhance the use of AAC in classrooms as supported by previous studies (Finke et al., 2009; Soto et al., 2001a;Soto et al., 2001b; Soto, 1997).

Finally, since the participants have positive perceptions toward teaching students with SCI, this study suggests it is essential for pre-service teachers to be encouraged to take more training, either through pre-service teacher education or through professional development programs, once they are teaching. As previously mentioned, this study suggests that teachers' lack of self-confidence in their own abilitites and in the capabilities of the students is the greatest barrier to successful inclusion of students who use AAC in classrooms (Soto, 1997). Overall, this study provides information on how special education training programs prepare teachers to utilize AAC to address the needs of students with SCI.

\section{Recommendations for Future Research}

First, since the sample of the study was limited in size and demographics, future researchers should consider replicating this study with a larger sample of pre-service special education teachers and include participants from across the United States, in order to obtain more reliable results. In addition, future researchers might conduct a study to determine if there are significant differences among participants from different existing preparation programs. Future research might address in-service teachers increasing their understanding of what specific skills are missing and to achieve the most accurate results possible.

Future researchers might also conduct a comparison study between in-service and pre-service special education teachers to determine if a difference exists. Since only pre-special education teachers participated in this study, future research might include teacher educators for greater understanding about pre-service training on AAC. This might help to discover what AAC contents are missing and need to be included in preparation programs. In addition, future research might include SLP, general education teachers, principals, administration staff and parents when addressing the use of AAC in inclusive classrooms. This could help to investigate perspectives toward using $\mathrm{AAC}$ and what essential skills and factors contribute to 
the successful use of AAC with students. This would also help teacher educators determine and develop what contents need to be included in the preparation programs for future teachers, and how often the preparation programs may need to be updated.

To close, future research might include using different types of research designs, not just the survey method by applying qualitative method research, mixed-method research or experimental method research. This would help to understand more about how participants deal with AAC, and then could determine which skills should be provided throughout pre-service training programs as well as through professional development programs. This would help close the gap between preparation training and actual practice.

\section{Conclusion}

The study was conducted to explore pre-service special education teachers' perceptions regarding their skills and knowledge about the use of AAC. Overwhelmingly, the participants had positive perceptions regarding teaching students with SCI. The findings also indicate that most participants felt positive about using AAC in classrooms. Although in general most participants felt confident about developing communication goals for their students who use AAC, many were negative about their ability to properly assess communication, identify and implement AAC. This indicates that pre-service training had not provided adequate skills and knowledge needed to use AAC in classrooms. In addition, the findings show that the majority of participants felt positively that parent involvement, along with collaboration with other professionals such as SLP, is necessary in assessing communication needs and teaching students as well as in successful use of AAC. Generally, the findings point out that most of the participants did not believe they had gained through their college education courses the skills necessary to assess communication needs of students, in order to successfully access and implement AAC. Finally, this study provides suggestions for future research and implications for practice. Further studies should consist of conducted research to obtain more information about pre-service and in-service teacher trainings on using AAC, and how to better provide necessary skills to deal with the use of AAC in classrooms. It is also evident that stakeholders need to address improving and updating the coursework and practica for preparing qualified teachers to support the use of AAC with students with severe communication impairments.

\section{Acknowledgement}

I would like to extend sincere appreciation to the Research Center of College of Education and Deanship of Scientific Research at King Saud University for funding this study.

\section{References}

Alkahtani, K. D. F. (2013). Teachers' knowledge and use of assistive technology for students with special educational needs. Journal of Studies in Education, 3(2), 65-86. https://doi.org/10.5296/jse.v3i2.3424

Alquraini, T. (2014). Factors that affect the use of assistive technology with students with multiple disabilities in their institutions and the attitudes of teachers toward this use. Journal of 
Educational

Studies,

26(3),

559-82.Retrieved

fromhttps://jes.ksu.edu.sa/sites/jes.ksu.edu.sa/files/v26n32014-3_0.pdf

American Speech-Language-Hearing Association [ASHA]. (2001). Roles and responsibilities of speech-language pathologists with respect to augmentative and alternative comunication: Position statement. Retrieved September 25, 2015, from http://www.asha.org/policy/PS2005-00113/

Andrews, K. (2007). Augmentative and alternative communication: General education teachers' attitudes and knowledge (Unpublished master's thesis). University of Kansas. Available from ProQuest Dissertations \& Theses A\&I. (304857512) Retrieved from http://search.proquest.com/docview/304857512

Ary, D., Jacobs, L., \& Razavieh, A. (2010). Introduction to research in education (8th ed.). Belmont, CA: Cengage Learning, Inc.

Bailey, R. L., Parette Jr., H. P., Stoner, J. B., Angell, M. E., \& Carroll, K. (2006). Family members' perceptions of augmentative and alternative communication device use. Language, Speech, and Hearing Services in Schools, 37(1), 50-60. http://doi:10.1044/0161-1461(2006/006).

Beukelman, D. R., \& Mirenda, P. (2005). Augmentative \& alternative communication: Supporting children \& adults with complex communication needs (3rd ed.). Baltimore, MD: Paul H. Brookes Publishing Co.

Bhattacherjee, A. (2012) Social science research: Principles, methods, and practices. Tampa, Florida. Retrieved from http://scholarcommons.usf.edu/cgi/viewcontent.cgiarticle $=100$

Chung, Y.-C., Carter, E. W.,\& Sisco, L. G. (2012). Social interactions of students with disabilities who use augmentative and alternative communication in inclusive classrooms. American Journal of Intellectual and Developmental Disabilities, 117(5), 349-67. http://doi:10.1352/1944-7558-117.5.349

Chung, Y.-C., \& Douglas, K. H. (2014). Communicative competence inventory for students who use augmentative and alternative communication: A team approach. Teaching Exceptional Children, 47(1), 56-68.https://doi.org/10.1177/0040059914534620

Collins, B. C. (2007). Moderate and severe disabilities: A foundational approach. Upper Saddle River, NJ: Pearson - Merrill Prentice/Hall.

Costigan, F. A., \& Light, J. C. (2010). A review of preservice training in augmentative and alternative communication for speech-language pathologists, special education teachers, and occupational therapists. Assistive Technology: The Official Journal of RESNA, 22(4), 200-12. https://doi.org/10.1080/10400435.2010.492774

Courtade, G., \& Ludlow, B. (2008). Ethical issues in severe disabilities: Programming for students and preparation for teachers. Rural Special Education Quarterly, 27(1-2), 36-42. Retrieved

from 
https://docs.google.com/viewer?a=v\&pid=sites\&srcid=ZGVmYXVsdGRvbWFpbnxnaW5ld nJhY291cnRhZGV8Z3g6MzQ1MTQ1Y2NkNjBiODUwNw

Crano, W., \& Brewer, M. (2002). Principles and methods of social research (2nd ed.). Mahwah, NJ.: Lawrence Erlbaum.

Finke, E. H., McNaughton, D. B., \& Drager, K. D. R. (2009). "All children can and should have the opportunity to learn": General education teachers' perspectives on including children with ASD who require AAC. Augmentative and Alternative Communication, 25(2), 110-22.https://doi.10.1080/07434610902886206

Fraenkel, J., \& Wallen, N. (2009). How to design and evaluate research in education, ( $\left.7^{\text {th }} e d.\right)$. Boston, MA: McGraw-Hill Higher Education.

Fricker, R. D., \& Schonlau, M. (2002). Advantages and disadvantages of Internet research surveys: Evidence from the literature. In Field Methods, 14(4), 347-367.https://doi.org/10.1177/152582202237725

Ganz, J. B. (2014). Aided augmentative communication for individuals with autism spectrum disorders. New York, NY: Springer.

Ganz, J. B., Earles-Volrath, T. L., Heath, A. K., Parker, R. I., Rispoli, M. J., \& Duran, J. B. (2012). A meta-analysis of single case research studies on aided augmentative and alternative communication systems with individuals with autism spectrum disorders. Journal of Autism and Developmental Disorders, 42(1), 60-74. https://doi.org/10.1007/s10803-011-1212-2

Hanline, M. F., Hatoum, R. J., \& Riggie, J. (2012). Impact of online coursework for teachers of students with severe disabilities: Utilization of knowledge and its relationship to teacher perception of competence. Research and Practice for Persons with Severe Disabilities, 37(4), 247-62. https://doi.org/10.2511/027494813805327269

Hourcade, J., Pilotte, T. E., West, E., \& Parette, P. (2004). A history of augmentative and alternative communication for individuals with severe and profound disabilities. Focus on Autism and Other Developmental Disabilities, 19(4), 235-44. https://doi.org/10.1177/10883576040190040501

Hunt, P., Soto, G., Maier, J., Müller, E., \& Goetz, L. (2002). Collaborative teaming to support students with augmentative and alternative communication needs in general education classrooms. Augmentative and Alternative Communication, 18(3), 20-35. http://dx.doi.org/10.1080/aac.18.1.20.35

Kent-Walsh, J., \& Light, J. C. (2003). General education teachers' experiences with inclusion of students who use augmentative and alternative communication. Augmentative and Alternative Communication, 19(2), 104-24. https://doi.org/10.1080/0743461031000112043

King, A. M., \& Fahsl, A. J. (2012). Supporting social competence in children who use augmentative and alternative communication. Teaching Exceptional Children, 45, 42-9. https://doi.org/10.1177/004005991204500106 
King, A. M., Hengst, J. A., \& DeThorne, L. S. (2013). Severe speech sound disorders: An integrated multimodal intervention. Language, Speech, and Hearing Services in Schools, 44(2), 195-210. https://doi.org/10.1044/0161-1461(2012/12-0023)

Koul, R. K., \& Lloyd, L. L. (1994). Survey of professional preparation in augmentative and alternative communication in speech-language pathology and special education programs. American Journal of Speech-Language Pathology, 3, 13-22.http://doi:10.1044/1058-0360.0303.13

Light, J. C., Arnold, K. B., \& Clark, E. A. (2003). Finding a place in the "Social circle of life": The development of sociorelational competency by individuals who use AAC. In Communication Competence for Individuals Who Use AAC: From Research to Effective Practice (pp. 361-97). Baltimore, MD: Paul H. Brookes Publishing Co.

Light, J., \& McNaughton, D. (2012). The changing face of augmentative and alternative communication: Past, present, and future challenges. Augmentative and Alternative Communication, 28(4), 197-204. https://doi.org/10.3109/07434618.2012.737024

Light, J., \& McNaughton, D. (2013). Putting people first: Re-thinking the role of technology in augmentative and alternative communication intervention. Augmentative and Alternative Communication, 29(4), 299-309. https://doi.org/10.3109/07434618.2013.848935

Lynn, M. R. (1986). Determination and quantification of content validity. Nursing Research, 35(6), 382-386.http://dx.doi.org/10.1097/00006199-198611000-00017

Millar, D. C., Light, J. C., \& Schlosser, R. W. (2006). The impact of augmentative and alternative communication intervention on the speech production of individuals with developmental disabilities: A research review. Journal of Speech, Language, and Hearing Research, 49, 248-64. Retrieved from http://www.isaac-nf.nl/m/Millar Light Schlosser 2006.pdf

Mirenda, P. (2005). Augmentative and alternative communication techniques. In J. E. Downing (Ed.), Teaching Communication Skills to Students with Severe Disabilities (2nd ed., pp. 89-112). Baltimore, MD: Paul H. Brookes Publishing Co.

National Research Council [NRC]. (2001). Educating children with autism. (Commitee on Educational Interventions for Children with Autism, C. Lord, \& J. P. McGee, Eds.). Washington, D.C.: National Academy Press. Retrieved from http://prismaticautism.com/wp-content/uploads/2015/04/National-Research-Study-.pdf

Nigam, R., \& Koul, R. (2009). Knowledge and skills and professional development needs in $A A C$. Poster session presented at the American Speech-Language Hearing Association Convention, New Orleans, LA. Retrieved from http://www.asha.org/events/convention/handouts/2009/1564_nigam_ravi/

Ogletree, B. T. (2007). What makes communication intervention successful with children with autism spectrum disorders? Focus on Autism and Other Developmental Disabilities, 22(3), 190-92. https://doi.org/10.1177/10883576070220030601 
Page, C. A., \& Quattlebaum, P. D. (2012). Severe communication disorders. In D. Hollar (Ed.), Handbook of Children with Special Health Care Needs (pp. 23-46). New York, NY: Springer. https://doi.org/10.1007/978-1-4614-2335-5_2

Partridge, J. (2009). The effects of augmentative and alternative communication devices on the intelligibility and speech rate of elementary school children. Speech Pathology \& Audiology Capstone Anthology (Vol. 1). Morgantown, WV. Retrieved from http://csd.wvu.edu/r/download/78053

Ratcliff, A., Koul, R., \& Lloyd, L. L. (2008). Preparation in augmentative and alternative communication: An update for speech-language pathology training. American Journal of Speech-Language Pathology, 17(1), 48-59. https://doi.org/10.1044/1058-0360(2008/005)

Rebelowski, G. I. (2003). Perspectives of paraprofessionals working with children using augmentative and alternative communication (AAC). (Unpublished master's thesis). Southern Connecticut State University, New Haven, CT.

Rispoli, M. J., Franco, J. H., van der Meer, L., Lang, R., \& Camargo, S. P. H. (2010). The use of speech generating devices in communication interventions for individuals with developmental disabilities: A review of the literature. Developmental Neurorehabilitation, 13(4), 276-93. https://doi.org/10.3109/17518421003636794

Soto, G. (1994). Teachers' attitudes toward the provision and use of augmentative and alternative communication systems by students with severe communication impairments: A structural equation model (Unpublished doctoral dissertation). Purdue University. Available from ProQuest Dissertations \& Theses A\&I. (304126931). Retrieved from http://search.proquest.com/docview/304126931

Soto, G. (1997). Special education teacher attitudes toward AAC: Preliminary survey. Augmentative and Alternative Communication, 13(3), 186-97. https://doi.org/10.1080/07434619712331278008

Soto, G., Müller, E., Hunt, P., \& Goetz, L. (2001a). Critical issues in the inclusion of students who use augmentative and alternative communication: An educational team perspective. Augmentative and Alternative Communication, 17(2), 62-72. https://doi.org/10.1080/714043369

Soto, G., Müller, E., Hunt, P., \& Goetz, L. (2001b). Professional skills for serving students who use AAC in general education classrooms: A team perspective. Language, Speech, and Hearing Services in Schools, 32(1), 51-56. https://doi.org/10.1044/0161-1461(2001/005)

Stoner, J. B., Beck, A. R., Bock, S. J., Hickey, K., Kosuwan, J., \& Thompson, J. R. (2006). The effectiveness of the "Picture Exchange Communication System" with nonspeaking adults. Remedial and Special Education, 27(3), 154-65. https://doi.org/10.1177/07419325060270030401 


\section{Macrothink}

Journal of Studies in Education

ISSN 2162-6952

2017, Vol. 7, No. 4

Subihi, A. S. (2013). Saudi special education student teachers' knowledge of augmentative and alternative communication (AAC). International Journal of Special Education, 28(3), 93-103. Retrieved from http://files.eric.ed.gov/fulltext/EJ1024412.pdf

U.S. Department of Education. (2010). Free appropriate public education for students with disabilities: Requirements Under Section 504 of The Rehabilitation Act of 1973. Retrieved March 16, 2015, from http://www2.ed.gov/about/offices/list/ocr/docs/edlite-FAPE504.html

Zangari, C., Lloyd, L., \& Vicker, B. (1994). Augmentative and alternative communication: An historic perspective. Augmentative and Alternative Communication, 10(1), 27-59. https://doi.org/10.1080/07434619412331276740

\section{Copyright Disclaimer}

Copyright for this article is retained by the author(s), with first publication rights granted to the journal.

This is an open-access article distributed under the terms and conditions of the Creative Commons Attribution license (http://creativecommons.org/licenses/by/3.0/). 